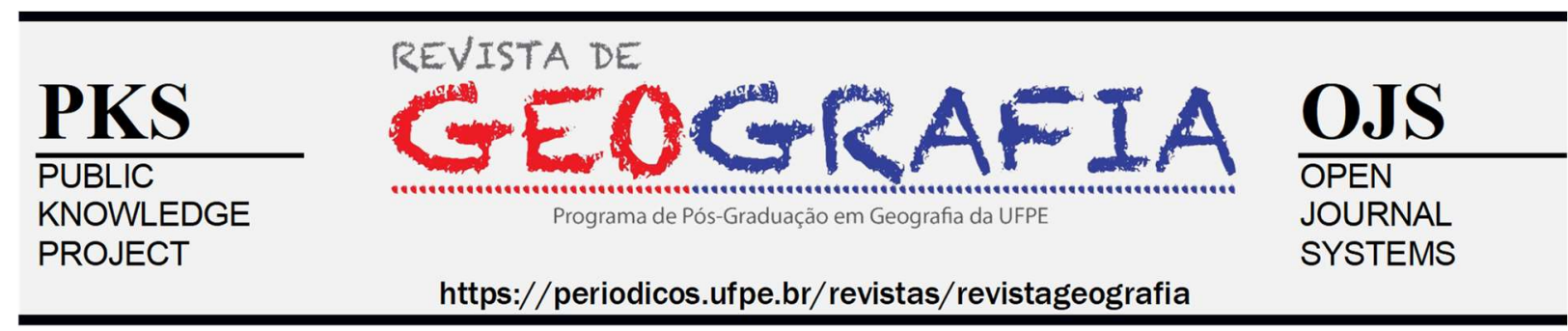

\title{
NA CAPITAL E NO INTERIOR: EXPERIÊNCIAS DO ESTÁGIO CURRICULAR SUPERVISIONADO NOS CURSOS DE LICENCIATURA EM GEOGRAFIA DA UNIVERSIDADE FEDERAL DO ACRE
}

\author{
Lucilene Ferreira De Almeida, Victor Régio da Silva Bento
}

\begin{abstract}
${ }^{1}$ Docente Adjunto III, do Centro de Filosofia e Ciências Humanas, Área de Geografia e do Programa de PósGraduação em Geografia, ambos da Universidade Federal do Acre. E-mail: lulucageo@gmail.com; http://orcid.org/0000-0002-2567-9983

2 Doutor em Geografia pela Universidade Estadual do Ceará - PROPGeo-UECE. Especialista em Geoprocessamento aplicado à análise ambiental e recursos hídricos. Atualmente é professor adjunto do curso de Geografia da Universidade Federal do Acre - UFAC. E-mail: victorbento@live.com; http://orcid.org/0000-00025167-3964
\end{abstract}

Artigo recebido em 30/06/2020 e aceito em 28/08/2020

\begin{abstract}
RESUMO
O presente trabalho traça um panorama sobre as diferentes formas de organização e prática do Estágio Curricular Supervisionado nos cursos de Licenciatura em Geografia da Universidade Federal do Acre, no recorte temporal 2014-2018. Esta instituição federal de ensino superior oferta seus cursos de graduação em diferentes modalidades, de acordo com as necessidades dos programas e projetos vinculados. O objetivo do artigo é apresentar e analisar os desafios de ministrar o estágio no curso regular de Licenciatura em Geografia, localizado no campus de Rio Branco, assim como no projeto de interiorização, no município de Sena Madureira e em um Programa de Formação de Professores, ministrado no município de Cruzeiro do Sul. Como recurso metodológico, além das análises das normativas que regulamentam este componente curricular, foram analisadas as vivências dos estagiários no espaço escolar e o processo de construção do relatório final da disciplina. Espera-se que este texto contribua para reflexões e atuações nos planejamentos e desenvolvimento dos estágios supervisionados em cursos de licenciatura, bem como para a construção dos Projetos Pedagógicos Curriculares, tendo em vista a importância deste componente para a formação docente.
\end{abstract}

Palavras-chave: Estágio Supervisionado; Formação docente; Licenciatura em Geografia.

\section{IN THE CAPITAL AND IN THE INTERIOR CITIES: EXPERIENCES OF SUPERVISED CURRICULAR INTERNSHIP IN GEOGRAPHY UNDERGRADUATE COURSES AT THE FEDERAL UNIVERSITY OF ACRE}

\section{ABSTRACT}

The present paper traces a panorama of the different organization forms and practices of Supervised Curricular Internship in Geography undergraduate courses at the Federal University of Acre, in 2014-2018 time frame. This federal higher education institution offers its undergraduate courses in different modalities, according to the needs of the linked programs and projects. This article highlights the challenges of teaching curricular supervised internship in the regular Geography undergraduate course, placed on Rio Branco campus, as well as in the 
interiorization project, placed in the municipality of Sena Madureira and in a Teacher Training Program, taught in the municipality of Cruzeiro do Sul. As a methodological resource, beyond to the analysis of regulations that rules this curricular component, were also analyzed interns experiences in school's environment and within the process of building the final report for the subject. Expectations are that this paper will contribute to reflections and actions in plannings and developments of supervised internships in undergraduate courses, as well as for the construction of Curricular Projects, bearing in mind of the importance of this component for teachers' training.

Keywords: Supervised Curricular Internship; Teacher training; Geography undergraduate.

\section{INTRODUÇÃO}

O Estágio Supervisionado é uma etapa obrigatória da estrutura curricular dos cursos de licenciatura, sendo um momento importante para a efetivação das experiências teóricas e práticas adquiridas no decorrer da graduação. Entendemos que o estágio não pode ser encarado como um componente curricular padronizado e homogêneo, visto que os cursos de licenciatura apresentam especificidades quanto aos horários de funcionamento, duração do curso e forma de execução das disciplinas.

O estágio é sempre uma etapa muito desafiadora para os alunos em formação. Quer seja na capital ou no interior, os desafios se intercruzam e despertam nos alunos estagiários ações e emoções para além de uma tecnicidade científica, tão comum na academia.

Atualmente, nos deparamos com uma diversidade de realidades que vão desde cursos presenciais até a modalidade à distância, incluindo ainda os cursos de formação de professores concentrados em alguns meses do ano e os projetos de interiorização. Dessa forma, surgem desafios para adequação dos componentes curriculares, implicando em várias formas de executar o estágio supervisionado.

Neste artigo apresentaremos as experiências como professores das disciplinas Estágio Curricular Supervisionado em Geografia I, II e III, componentes do curso de licenciatura homônimo. Na primeira parte do texto apresentamos algumas questões sobre o estágio obrigatório nos cursos de Licenciatura em Geografia da UFAC, incluindo as normativas que o regulamenta. Em seguida, abordamos sobre algumas modalidades de cursos de Geografia ofertados em diferentes municípios do Acre, apresentando as experiências nas disciplinas de estágio em cada um desses cursos.

Destacaremos aqui a concomitância das formas de execução do estágio supervisionado nos cursos de graduação de Licenciatura em Geografia, ofertados em três cidades acreanas: Rio Branco, com a modalidade regular; Sena Madureira, com o Projeto de Interiorização; e Cruzeiro do Sul, com o Programa de Formação de Professores - Parfor. Cada um destes cursos apresenta características próprias de sua forma da oferta e na organização dos componentes curriculares. 


\section{O ESTÁGIO CURRICULAR SUPERVISIONADO EM GEOGRAFIA DA UFAC}

A Lei 11.788, de 2008, dispõe sobre o estágio de estudantes e o define, em seu artigo primeiro, como: "ato educativo escolar supervisionado, desenvolvido no ambiente de trabalho, que visa à preparação para o trabalho produtivo de educandos que estejam frequentando o ensino regular". (BRASIL, 2008, p.1). Nesse sentido, o estágio é entendido como etapa do processo de formação, que permite a vivência da atividade profissional, na qual o licenciado está se capacitando.

É o ato de estagiar que mais vai caracterizar a relação teoria-prática dentro do contexto de formação de professores. Entretanto, o estágio não se limita apenas a esta relação, devendo ser considerado enquanto campo social das práticas docentes e campo de atividades de pesquisa. Assim, adquire "um estatuto epistemológico que supera sua tradicional redução à atividade prática instrumental.” (LIMA; PIMENTA, 2006, p. 06).

O estágio é componente curricular obrigatório na Licenciatura em Geografia e está definido no projeto do curso, pelo que determina a Lei 11.788/2008 (BRASIL, 2008). Este documento atribui as diretrizes para sua oferta, definindo entre outros sobre: a distribuição da carga horária mínima estabelecida (a Resolução $\mathrm{CNE} / \mathrm{CP}$ n. 2 determina a carga horária mínima do curso a 400 horas-aula, os campos do estágio (as escolas ou espaços alternativos); o professor orientador; o professor receptor ou supervisor; objetivos e formas de avaliação.

Além da Lei 11.788/2008, institucionalmente os estágios estão estabelecidos no Regimento Interno da UFAC, na Seção XXIV - Do Estágio Curricular - Artigos 365, 366, 367, 368 e 370, na Resolução nº 02 do CNE/CP 2 de 2002, na Resolução nº 202 do CNE/CP 2 de 2015 e na Resolução nº. 014/2010 do CEPEX.

O curso de Licenciatura em Geografia da Universidade Federal do Acre - UFAC dedica 405 horas-aula para os estágios curriculares, em seus três últimos semestres. Sendo assim, possui relevância para a formação de professores, os quais irão atuar nas mais diversas etapas da educação básica e superior.

O Estágio Curricular Supervisionado em Geografia, segundo o Projeto Pedagógico Curricular do Curso, está organizado em três disciplinas. Elas são oferecidas a partir do sexto período do curso, sendo assim distribuídas: Estágio Curricular Supervisionado em Geografia I: observação do ambiente escolar e das aulas de Geografia, acompanhamento das diversas atividades do professor de Geografia, nos anos finais do Ensino Fundamental II e Ensino Médio 
(regular e/ou outras modalidades), correspondendo a 90 horas-aula, no $6^{\circ}$ período letivo; Estágio Curricular Supervisionado em Geografia II: observação, planejamento e regência nos anos finais do Ensino Fundamental II (regular e/ou outras modalidades), correspondendo a 135 horas-aula, no $7^{\circ}$ período letivo; e Estágio Curricular Supervisionado em Geografia III: observação, planejamento e regência no $1^{\circ}, 2^{\circ}$ e $3^{\circ}$ anos do Ensino Médio (regular e/ou outras modalidades), correspondendo a 180 horas-aula, no $8^{\circ}$ período letivo.

Atualmente esta organização dos estágios passa por algumas mudanças, tendo em vista a reformulação do PPC do Curso de Licenciatura em Geografia da UFAC, com previsão de implantação a partir do primeiro semestre de 2021. Os estágios permanecerão com a carga horária total de $405 \mathrm{~h}$, porém com reestruturação na distribuição das horas-aula e em suas ementas. Na proposta, cada um dos estágios terá carga horária de $135 \mathrm{~h}$ e contemplarão etapas de observação, planejamento e regência, sendo assim organizados: o Estágio Curricular Supervisionado em Geografia I será realizado no $6^{\circ}$ e $7^{\circ}$ ano do Ensino Fundamental regular e outras modalidades de ensino; o Estágio Curricular Supervisionado em Geografia II, no $8^{\circ}$ e $9^{\circ}$ ano do Ensino Fundamental regular e outras modalidades de ensino; e o Estágio Curricular Supervisionado em Geografia III, será voltado para o Ensino Médio regular e outras modalidades.

Para além das questões legais e normativas, o estágio enquanto componente curricular, possibilita reflexões sobre a prática docente. É nele que muitos alunos, mesmo estando em um curso cuja formação é para a docência, tomam posturas quanto a sua construção identitária docente. Os diversos desafios os levam a se posicionarem sobre o ser ou não ser professores.

A Universidade Federal do Acre é a única instituição pública de ensino superior acreana, com o campus sede localizado na capital, Rio Branco. Nesse sentido, a descentralização das ações para além da sede sempre foi uma necessidade, principalmente pelas condições geográficas regionais, com destaque para as distâncias entre a capital e os municípios mais afastados. Isso se agrava pelas condições da principal via de ligação entre os municípios, a BR364, que é precariamente pavimentada e em períodos chuvosos torna-se intrafegável em muitos trechos. Outro agravante é o preço alto do transporte aéreo, única alternativa para deslocamento em determinados períodos do ano em alguns municípios acreanos. 
Nesse sentido, a UFAC passa a atuar nos municípios acreanos, descentralizando sua atuação: passa a ofertar no interior diversos cursos, com o objetivo de atender a demanda de formação superior no estado ${ }^{1}$.

\section{O ESTÁGIO SUPERVISIONADO NO CURSO REGULAR DE LICENCIATURA EM GEOGRAFIA}

O curso de Licenciatura em Geografia no campus sede da UFAC, em Rio Branco, ocorre no turno matutino, de segunda a sábado. O Estágio I é ministrado de forma concomitante às outras disciplinas do sexto período, com 1 encontro semanal, de 6 h/a (50 minutos, cada), durante todo o semestre. Os demais estágios ocorrem preferencialmente de forma blocada no semestre, para facilitar a execução das atividades de regência, assim como a lotação nas escolas. No Estágio II são 27 encontros seguidos, de 6 h/a (50 minutos, cada), no sétimo período do curso. O Estágio III, com maior carga horária, ocorre em 36 encontros de 6 h/a (50 minutos, cada), no último período do curso.

Em Rio Branco mesmo com o número suficiente de escolas que oferecem educação básica, há a princípio uma dificuldade de acesso a algumas dessas unidades de ensino, que negam a recepção do estágio, mesmo que haja acordo de cooperação entre a Secretaria de Estado de Educação (SEE/AC) e a UFAC.

A existência do Colégio de Aplicação - CAp/UFAC, que tem como finalidade dar suporte às atividades didático-pedagógicas dos cursos de licenciatura da instituição, facilita de certo modo algumas atividades de estágio. Entretanto, o pouco número de turmas do colégio não favorece a lotação de todos os estagiários na mesma unidade de ensino. Desse modo, as turmas de estagiários são também distribuídas pelas escolas estaduais.

Compete ao professor orientador, em parceria com o Coordenador de estágio “conhecer o campo de estágio e estabelecer um contato inicial com o supervisor do campo, apresentando a ementa do estágio e verificando a compatibilidade das atividades desenvolvidas no campo com a formação do aluno". (UFAC, 2017, p. 14)². Vencida a definição das escolas que serão

\footnotetext{
${ }^{1}$ Sobre esse processo de descentralização da atuação da UFAC para além do campus sede em Rio Branco, existem alguns trabalhos que tratam da interiorização e dos diversos programas nesse sentido, como de Gondim, Silva e Lima (2015); Carvalho, Pires e Verçosa (2015).

${ }^{2}$ A Resolução no ${ }^{\circ}$ 19, de 22 de maio de 2017, em seu Art. 4 assim define: Professor orientador, docente responsável pelo acompanhamento do planejamento, execução e avaliação das atividades de estágio; Coordenador de estágio, docente indicado pela Assembleia de Centro para realizar, juntamente com a Diretoria de Apoio à Formação Acadêmica - Diafac, articulações necessárias quanto aos trâmites burocráticos do estágio, bem como realizar reuniões periódicas com os professores de estágio de seu curso; Supervisor/Preceptor de Estágio:
} 
campo de execução do estágio, juntamente com as demais providências do planejamento, os trabalhos tomam outra dimensão e os desafios passam a ser também dos alunos estagiários, que irão vivenciar as diferentes etapas da prática de ensino.

Nesse período de observações e pesquisas nos trabalhos das disciplinas de estágio no curso de Licenciatura em Geografia no campus sede, em Rio Branco, destacamos alguns dos principais desafios identificados e os apresentamos a seguir:

- O planejamento enquanto momento de articular questões didáticas, teóricas e práticas voltadas ao contexto da escola. Colocar estas questões em prática é um desafio entre os alunos e, um ponto que se destaca é o fator tempo: "será que o que planejei é suficiente para o tempo de aula?", "e se sobrar tempo?”, “e se faltar tempo”? Esses questionamentos geram certa aflição nos alunos, pois há inseguranças quanto ao conseguir "preencher" todo o tempo da aula. Nesse sentido, é importante que o professor orientador considere este fator comum para quem ainda não tem experiência na atuação docente. A delimitação do tempo para cada ação realizada em sala de aula é importante, tanto para organização do plano de aula quanto para sua execução.

Outra questão correlata diz respeito à perspectiva do professor enquanto pesquisador, que se efetiva muito na prática do planejamento do estágio. Muitas das vezes, há pouca autonomia para pesquisar sobre as temáticas das aulas, sobre metodologias mais interessantes e indicadas para o ano escolar. Recorrer a aulas prontas, encontradas na internet marca uma das primeiras iniciativas do aluno estagiário, por isso a necessidade do acompanhamento e mediação do professor orientador em todo o processo de planejamento das aulas.

Para Libâneo (1991), o planejamento é um processo de sistematização e organização das ações do professor. É um instrumento da racionalização do trabalho pedagógico que articula a atividade escolar com os conteúdos do contexto social. Por isso, é importante que os alunos estagiários entendam a relevância de um planejamento consciente, onde a construção de cada etapa precisa ser pautada no conhecimento e compreensão daquilo que será ensinado, como será ensinado e para quem será ensinado.

- O momento da aula: como professor de geografia em formação e em observação. Com o planejamento construído (conteúdos e metodologias definidos), do aluno estagiário esbarra em outro desafio, qual seja, ser observado e avaliado pelo preceptor de estágio e pelo professor orientador. O primeiro, já formado e com experiência na docência, já é acostumado com a

profissional da área de formação que supervisionará o estagiário no campo de trabalho. No caso, professores de Geografia nas escolas. (UFAC, 2017). 
turma, conhecedor do conteúdo a ser trabalhado, entre outros; o segundo, o professor que o orienta nas tarefas do estágio e que irá avaliá-lo de modo mais crítico. Isso tem um peso para o aluno estagiário, afinal, quem se sente tranquilo ao ser avaliado? No entanto esta é uma etapa do estágio que precisa ser vencida, pois faz parte do processo.

É importante que a avaliação do estagiário durante a aula ministrada, seja entendida por quem o observa e o avalia, como um momento importante em sua formação, mas que é permeado de tensão e insegurança. Deve-se também considerar que, por estar em desenvolvimento formativo, ele continua sendo aluno e o processo de ensino e aprendizado precisa existir. Há de considerar que não podemos exigir do estagiário práticas que só com a experiência docente são construídas.

- A educação inclusiva na prática da disciplina de Geografia: o que fazer? Apesar de serem poucas as experiências, este tem sido um dos desafios que os alunos estagiários de Rio Branco destacam em seus relatórios e apresentações dos trabalhos finais das disciplinas. Há preocupação nos estagiários quando verificam a presença de Pessoas com Deficiência - PcD nas escolas, pois elas precisarão ser incluídas no planejamento e atividades das aulas.

Mesmo com disciplinas no currículo do curso que ajudam os licenciandos a compreender a questão da educação inclusiva e os direcionam a pensar em metodologias variadas, a prática é bem mais desafiadora. Não deve haver negligência por parte do estagiário com os alunos identificados como $\mathrm{PcD}$, pois essa é uma excelente oportunidade de desenvolver metodologias e materiais para o uso na escola, em parceria com os professores.

Nesse sentido, a legislação é explícita quanto a obrigação das escolas em acolher todos os alunos, mas o importante é que esse atendimento não seja meramente uma formalidade, e que o aluno com deficiência tenha condições de se realizar em suas potencialidades. (LIMA, 2006).

Algumas propostas de trabalhos voltados para a inclusão têm sido desenvolvidas e compartilhadas nas aulas de Geografia, dentre as quais: representações espaciais táteis, como mapas, estruturas da terra, tipos de relevo, dentre outros; trabalhos com música e exibição de filmes ou documentários com narração para deficientes visuais. Mas, como o aluno estagiário lida com tudo isso? Como o ato de planejar e ministrar a aula já é desafiador, muitos não conseguem dar conta dessa especificidade metodológica.

Em alguns casos nos reunimos (estagiário, professor da turma e professor orientador) e juntos definimos atividades diferenciadas para os alunos PcD. Aqui, mais uma vez reforçamos 
a necessidade e importância da pesquisa na prática docente. Identificamos que este é um desafio para o próprio professor da turma, que em certos momentos pedia-nos ajuda e passava a compartilhar dos materiais e propostas construídos pelos estagiários.

Outros desafios e reflexões foram identificados durante os estágios com as turmas em Rio Branco, mas optamos em destacar os anteriormente mencionados, por serem os que mais se repetem em nossos anos de experiência com Estágio Supervisionado. Entendermos este componente curricular como parte do processo de formação do aluno e vemos a necessidade de orientação e acompanhamento por parte do professor orientador em todas as suas etapas.

\section{O ESTÁGIO SUPERVISIONADO NO PROJETO DE INTERIORIZAÇÃO}

No município de Sena Madureira, o curso de Licenciatura em Geografia foi ofertado por meio do programa de interiorização da UFAC, que é realizado em parceria com o Governo do Estado, por meio da Secretaria Estadual de Educação e prefeituras municipais. O Programa de Interiorização do Ensino de Graduação foi implantado em 1973 “no intuito de descentralizar suas atividades acadêmicas e minimizar as dificuldades da população interiorana do Acre, no que diz respeito ao acesso ao ensino superior.” (BEZERRA, 2009, p. 16).

Essa modalidade de ensino envolve diversos programas, que se intensificaram a partir da LDBEN n ${ }^{\circ}$ 9.394/96, a qual institui a obrigatoriedade da formação superior de professores para a educação básica. A interiorização possibilita maior descentralização das ações para além do campus sede, em Rio Branco e atua inclusive em municípios de difícil acesso.

O programa de interiorização em Sena Madureira já formou três turmas de licenciatura em Geografia: 2001-2005, 2007-2010 e 2015-2018, com o Programa Especial de Formação de Professores para Educação Básica - Licenciaturas Específicas. Os cursos foram implantados numa organização de módulos de 30h semanais, realizados no turno da manhã. Dessa forma, os estágios foram organizados na seguinte estrutura: Estágio I - 3 semanas. Estágio II - 4 semanas e meia; e Estágio III - 6 semanas.

O desenvolvimento dos estágios supervisionados na turma 2015-2018 ocorreu em três instituições de ensino, a saber: Escola Estadual (EE) de Ensino Fundamental Fontenele de Castro; Escola Assis Vasconcelos - anexo da EE de Ensino Fundamental Raimundo Hermínio de Melo; e a EE Ensino Médio Dom Júlio Mattioli (Figura 01).

Sena Madureira apresenta algumas especificidades no provimento educacional. É o terceiro maior município do Acre em população total e urbana e, consequentemente, tem uma 
demanda crescente pela educação básica. É o segundo maior município acreano em extensão territorial, com uma população distribuída de forma dispersa em povoados e colocações no curso de seus principais rios, logo, necessita da formação de docentes para atender a zona rural. Apresenta-se como polo de sua região imediata (microrregião), exercendo influência sobre os municípios de Manoel Urbano e Santa Rosa do Purus. Entretanto, os programas de interiorização atendem majoritariamente a sua demanda interna na formação de professores.

A cidade tem uma área urbana em crescente expansão, com a formação de bairros cada vez mais distantes de seu centro. Assim, verifica-se a necessidade de descentralização da educação básica para outras localizações. Tal característica foi observada no momento da execução do Estágio III, que corresponde ao Ensino Médio. Essa etapa, na rede pública de ensino, está concentrada na EE Dom Júlio Matiolli.

Figura 01- Escolas receptoras dos estagiários em Sena Madureira

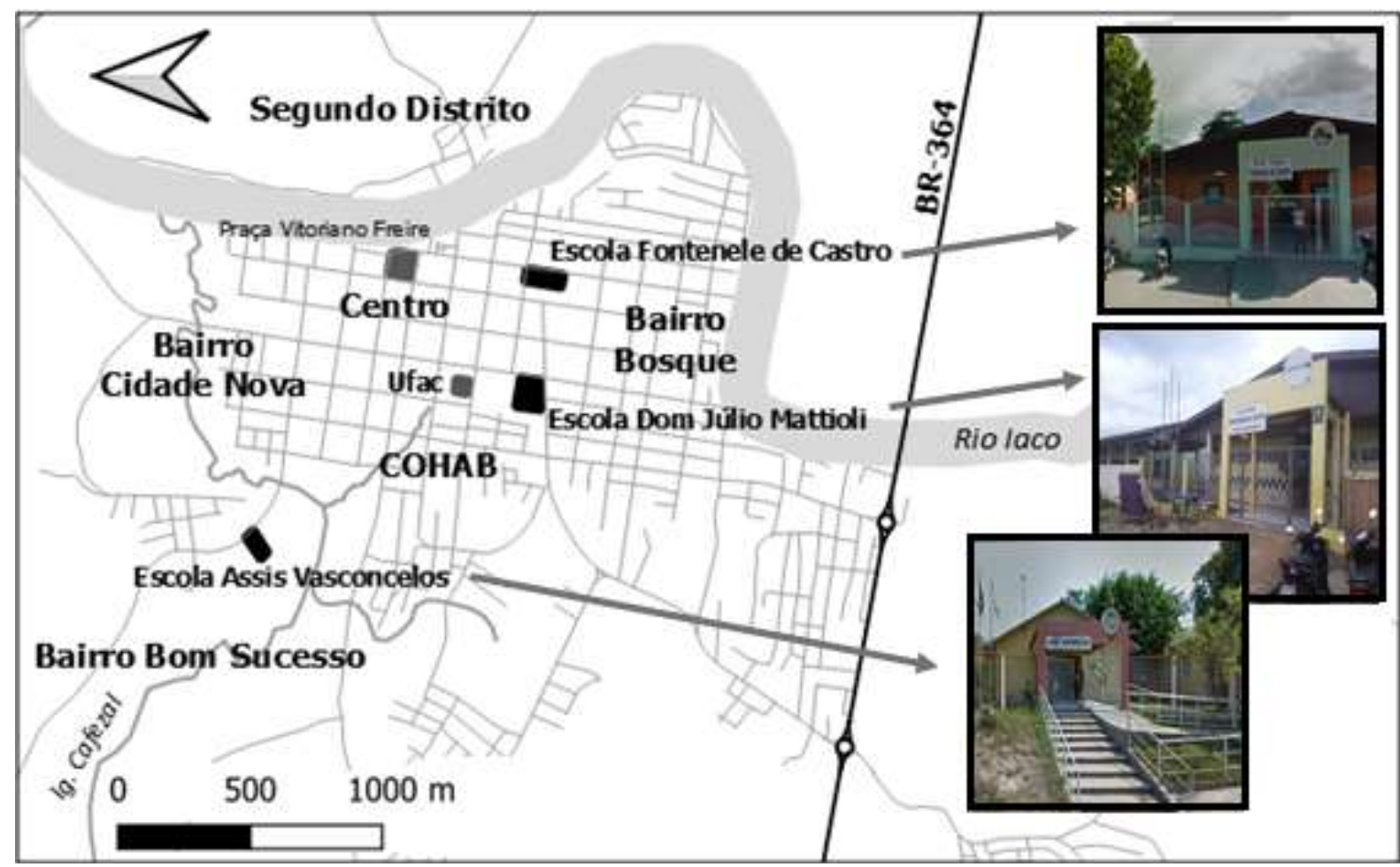

Fonte: Elaborado por BENTO, V. R. S. (2020)

Como obstáculos da falta de descentralização educacional, os estudantes dessa escola percorrem distâncias significativas, ademais, ocorrem empecilhos para execução do Estágio Supervisionado. Conseguimos resolver a distribuição dos estagiários ao detectarmos três turmas de Ensino Médio na escola Assis Vasconcelos, em um anexo improvisado. A instituição 
localiza-se em uma área periférica de Sena Madureira e foi bastante receptiva quanto às atividades dos Estágio II e III.

Para a maioria dos alunos da interiorização de Sena Madureira, a Licenciatura em Geografia foi o primeiro curso superior e, portanto, os estágios são suas primeiras experiências como docentes. Dentre as principais questões destacadas pelos alunos como desafios, algumas são comuns ao da modalidade regular, outras são mais específicas, a partir das particularidades da cidade e da forma de oferta do curso.

- Primeira experiência docente. Assim como na capital, este é também um desafio apontado pelos alunos de Sena Madureira. Executar a prática docente é um dos momentos do estágio que causa inquietações nos licenciados. Porém, a apreensão aumenta ao saber que assumirão a sala de aula tendo a presença do professor da educação básica e do supervisor da disciplina.

- Estrutura das escolas. Algumas escolas não são diferentes das existentes na capital acreana quanto as dificuldades estruturais. Destacamos as poucas opções de recursos e materiais didáticos, o desconforto térmico gerado pela ausência de ar-condicionado e/ou ventilador, assim como salas improvisadas para atender parte da demanda do Ensino Médio. Tais fatores tornaram inviáveis algumas atividades que poderiam ter sido realizadas com as turmas.

Mesmo com tais dificuldades, observamos que a turma da sala com piores condições estruturais obteve melhor participação e interesse nas atividades propostas. Essa experiência gerou duas importantes reflexões para os estagiários e supervisores: 1) O planejamento e a atuação do professor são essenciais para aproveitar o que há disponível no espaço escolar; 2) incentivar o potencial dos alunos é mais importante que os melhores recursos e estruturas.

- O desafiador planejamento das aulas. Como este ponto é também recorrente entre os alunos estagiários do curso em Sena Madureira, retomamos ele aqui, apenas para reforçar a necessidade de maiores reflexões nesta etapa que é importante e considerada fundamental para a formação docente. Dentre os apontamentos destacados pelos licenciados ressaltamos: a dificuldades na elaboração do plano de aula, especialmente quanto aos procedimentos metodológicos e as formas de avaliação da turma; e a escolha de materiais didáticos que possibilitem uma aprendizagem lúdica, como jogos e brincadeiras.

Estes são pontos que podem ser comuns durante o estágio, mas que, em Sena Madureira foram mais marcantes e se destacaram no seminário final e nos relatórios. 


\section{O ESTÁGIO SUPERVISIONADO NO PROGRAMA NACIONAL DE FORMAÇÃO DE PROFESSORES DA EDUCAÇÃO BÁSICA - PARFOR}

O curso de Licenciatura em Geografia, no município de Cruzeiro do Sul (turma 20142017), fez parte do Plano Nacional de Formação de Professores da Educação Básica - Parfor. Na modalidade presencial, o programa de caráter emergencial foi implantado em regime de colaboração entre a União, por meio da Capes (Coordenação de Aperfeiçoamento de Pessoal de Nível Superior), estados e municípios, com envolvimentos das IES (Instituições de Educação Superior). O Parfor atende professores que estão no exercício da docência, na rede pública, mas que não possuem curso de formação superior nas áreas nas quais atuam.

A UFAC, como única instituição federal de ensino superior do Acre, assume a responsabilidade de gestão organizacional e pedagógica dos cursos ofertados no interior. Em 2014 tem início o curso de Licenciatura em Geografia, sediado em Cruzeiro do Sul. Com 37 alunos matriculados, essa graduação atende as demandas dos municípios do Vale do Juruá. A turma era composta por alunos oriundos tanto da cidade sede, quanto de Mâncio Lima, Rodrigues Alves, Marechal Thaumaturgo e do município amazonense de Guajará.

A execução do estágio supervisionado pelo Parfor apresentou algumas características que o diferenciou do curso regular (em Rio Branco) e da interiorização (em Sena Madureira). Uma delas é que os discentes já possuem uma formação adquirida em cursos de Magistério ou em outras graduações como Pedagogia, História e Letras. Desse modo, a licenciatura em Geografia é uma formação complementar para os que desejam lecionar nas séries finais do Ensino Fundamental e no Ensino Médio ou para adquirir habilitação em outra disciplina.

A prática em sala de aula por parte dos estagiários foi uma questão considerada tanto pelos professores orientadores e professores regentes, nas escolas que os receberam. A experiência em sala de aula significou um ponto positivo para a execução das atividades do estágio supervisionado, pois facilitou a interlocução com a comunidade escolar, assim como nas atividades de planejamento e regência. Tendo em vista que ensinar não era "novidade", o que agregou aos alunos do Parfor foi a aplicação dos conteúdos específicos da disciplina de Geografia, indo para além da polivalência presente na prática pedagógica dos anos iniciais do Ensino Fundamental.

Outro diferencial decorreu do cronograma das graduações do Parfor. Por atender professores que atuam em escolas rurais, o curso funciona apenas nos meses das férias escolares, período este reprogramado pelas secretarias municipais de educação. Essa forma de 
organização atende a demanda por formação superior e ao mesmo tempo não interfere no cumprimento da carga horária das escolas. A concentração das aulas em um breve período (geralmente entre dezembro e março) repercutiu na organização das estruturas curriculares dos cursos de graduação.

No caso da Licenciatura em Geografia, as disciplinas tiveram que ser ministradas por dez horas-aula diárias, de segunda a sábado. Consequentemente, os estágios foram readequados da seguinte forma: Estágio I - 9 dias, Estágio II - 14 dias e Estágio III - 18 dias. O tempo exíguo para execução das diversas atividades referentes à estes componentes disciplinares consistiu em um desafio tanto para os professores supervisores quanto para os estagiários, que tiveram que cumprir as seguintes etapas: contato preliminar com a escola, discussão textual, observação do espaço escolar, aplicação de entrevistas, planejamento de aulas, confecção do plano de aula, atividades de regência, elaboração do relatório final.

As atividades de observação, planejamento e regência do estágio foram realizadas nas escolas estaduais João Kubitschek e Madre Aldegundes Becker situadas em Cruzeiro de Sul, além da Escola Estadual Antônio Oliveira Dantas e Colégio São Francisco, em Mâncio Lima. O ponto de apoio para recepção dos professores em formação foi o Centro de Formação e Tecnologia da Floresta - Ceflora, vinculado à UFAC (Figura 02).

Figura 02 - Escolas receptoras dos estagiários Parfor

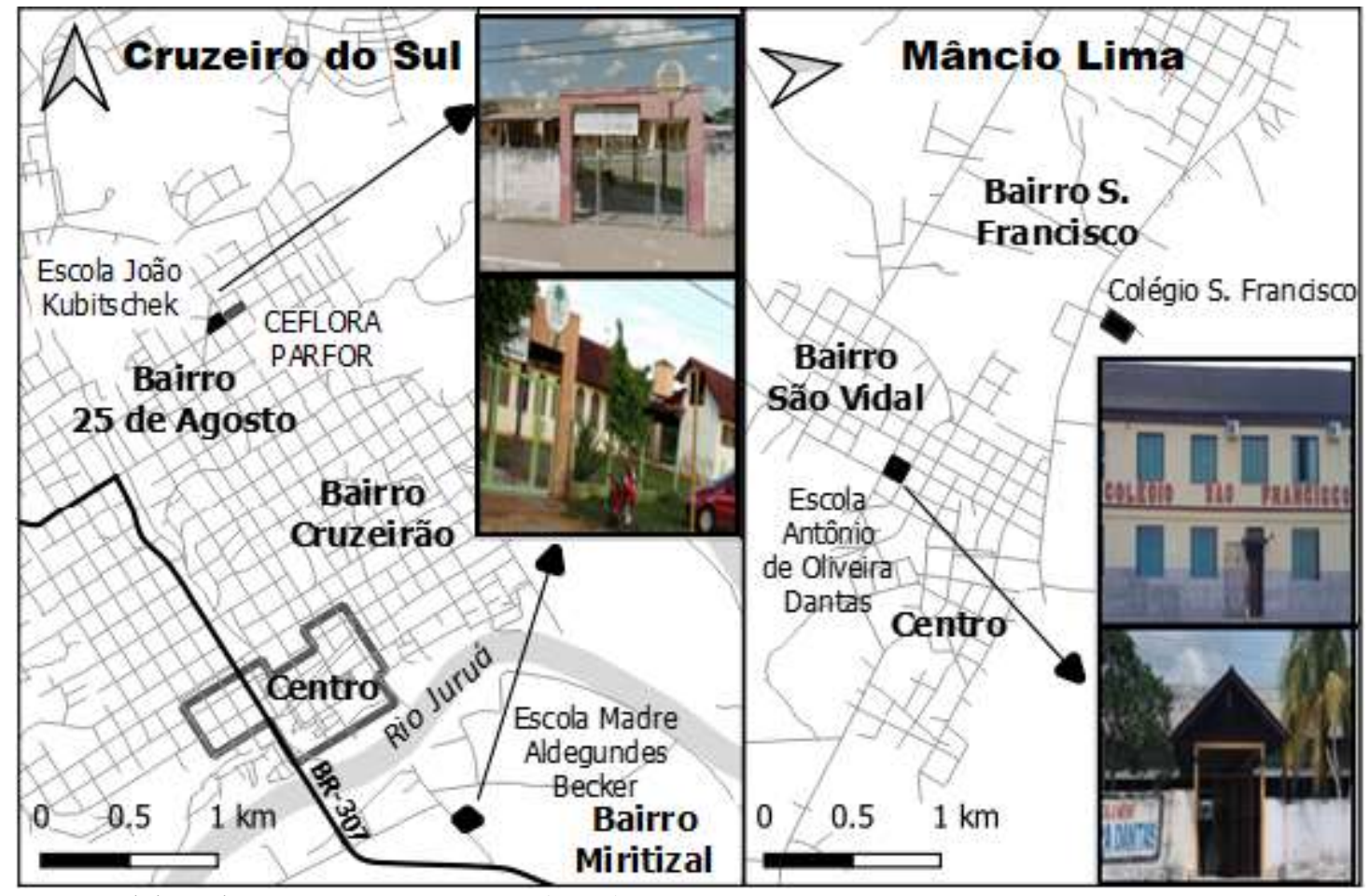

Fonte: Elaborado por BENTO, V. R. S. (2020) 
A socialização dos Estágios Supervisionados I e II em Cruzeiro do Sul propiciou um amplo debate sobre os desafios em realizar este componente curricular. Os discentes da disciplina ressaltaram os desafios encontrados, tanto no aspecto da infraestrutura das escolas visitadas, quanto nos aspectos sociais dos bairros onde se situam estas instituições. Além disso expuseram as dificuldades na elaboração do relatório de estágio.

- As dificuldades na elaboração do relatório final: foram oriundas do caráter concentrado da disciplina, incidindo na produção textual, formatação e no amadurecimento das reflexões textuais destinadas ao referencial teórico. Os estagiários tiveram que conciliar o relatório com a longa jornada diária de aula, somada ao deslocamento para suas residências (alguns retornavam diariamente para os municípios vizinhos), além de suas atividades cotidianas extrassala.

- Aspectos sociais do entorno da escola: as instituições de ensino que receberam os docentes refletem a realidade de suas respectivas comunidades. A EE Madre Aldegundes Becker situa-se no bairro Miritizal e está em uma área de vulnerabilidade socioambiental, tanto pela proximidade do Rio Juruá (estando sujeita às alagações) quanto pela segregação urbana. Por estar inserida em um bairro com precariedade no saneamento, o abastecimento de água dessa escola é realizado via poço artesiano e a captação de efluentes é destinada à fossa séptica. Já a EE João Kubitschek está localizada nas imediações do Ceflora, o que facilitou o deslocamento dos estagiários. Seu entorno é caracterizado por melhor infraestrutura, com diversidade de atividades comerciais e próximo ao Batalhão da Polícia Militar, demonstrando melhores condições de segurança.

- Disparidades na estrutura das escolas: detectou-se na EE Madre Aldegundes Becker a ausência de dependências básicas como biblioteca, laboratório de informática, laboratório de ciências e quadra esportiva, além de não possuir acessibilidade a pessoas com deficiência. Em contrapartida, o Colégio São Francisco é mantido pelo poder estadual em forma de convênio e apresenta uma boa estrutura: laboratório de informática, sala de música, biblioteca com diversos materiais didáticos; e amplo espaço arborizado. Essa escola possui sala de recursos para Atendimento Educacional Especializado - AEE e banheiro com acessibilidade, fatores que indicam uma capacidade de inclusão de pessoas com deficiência.

- Os desafios da profissão docente: os estagiários do Parfor, em sua rotina como professores, destacaram as dificuldades encontradas nos municípios do Vale do Juruá. Muitas escolas estão dispersas na zona rural e com difícil acessibilidade, seja pelas condições da estrada 
ou pela localização no alto curso dos rios. Em algumas situações, os docentes passam o período letivo morando na comunidade, às vezes em um cômodo improvisado na escola e só retornam para a sede municipal nas férias ou com a finalização do contrato. Os estabelecimentos de ensino rurais são construídos majoritariamente em madeira e o professor tem que assumir atribuições que vão além da docência dentre as quais: coordenador, merendeiro e auxiliar de serviços gerais.

As especificidades aqui apresentadas nos três municípios acreanos, refletem a dinâmica dos espaços e das gentes no desafio da formação docente local. Em todas elas evidenciamos a emergência de um olhar diferenciado para este componente curricular, que é o estágio. Nele, o estagiário precisa ser visto ainda como um aluno e, mesmo que já assuma tarefas de professor, a sua formação ainda está em processo.

\section{CONSIDERAÇÕES FINAIS}

O estágio é sempre uma etapa muito desafiadora para os alunos em formação. Quer seja na capital ou no interior, os desafios se intercruzam e despertam nos alunos estagiários ações e emoções para além de uma tecnicidade científica, tão comum na academia. As disciplinas de estágio, cumprem importante papel no processo de formativo dos graduandos e é durante esta experiência que os estagiários desenvolvem as práticas pedagógicas e vivenciam a transposição dos conteúdos acadêmicos para conteúdos escolares. Desafios como o planejamento das aulas, dificuldade com os conteúdos específicos da disciplina, além do fato de ser observado e avaliado durante a ministração das aulas pelo professor orientador estão presentes nas falas e relatos dos estagiários. Porém, para além dos vários desafios, é perceptível que há por parte dos licenciandos um esforço para que seu desempenho seja satisfatório, mesmo diante de realidades escolares muitas vezes adversas das vislumbradas por eles.

Nesse sentido, o estágio cumpre sua relevância curricular e pedagógica e, independente do contexto geográfico do curso, da turma e dos alunos, os desafios irão sempre existir, pois o campo de trabalho do estágio, que é a escola, por seu caráter complexo, resultará sempre em experiências diversas e heterogêneas. Importante é que, todos os envolvidos vivenciem o estágio enquanto parte do processo formativo, que necessita ser bem planejado, executado e avaliado. 


\section{REFERÊNCIAS}

BEZERRA, S. M. C. B. Interiorização da UFAC: qualificação profissional e sua influência no desenvolvimento do estado do Acre. Dissertação (Mestrado), Programa de Pós-graduação em Desenvolvimento Regional Universidade Federal do Acre. Rio Branco - AC, 2009, $159 f$.

BRASIL. Lei n.11.788 de 25 de setembro de 2008 (sobre estágio de estudantes). Brasília: Subchefia para assuntos jurídicos, 2008.

BRASIL. Conselho Nacional de Educação. Resolução CNE/CP n 2, de 19 de fevereiro de 2002, que institui a duração e a carga horária dos cursos de licenciatura, de graduação plena, de formação de professores da Educação Básica em nível superior. Disponível em: http://portal.mec.gov.br/cne/arquivos/pdf/CP022002.pdf. Acessado em: 27 de maio de 2019.

BRASIL. Conselho Nacional de Educação. Resolução CNE/CP n 2, de 01 de junho de 2015, que define as Diretrizes Curriculares Nacionais para a formação inicial em nível superior (cursos de licenciatura, cursos de formação pedagógica para graduados e cursos de segunda licenciatura) e para a formação continuada. Disponível em: http://portal.mec.gov.br/index.php?option=com_docman\&view=download\&alias=98191-rescp-02-2015\&categoryslug=outubro-2018-pdf-1\&Itemid=30192. Acessado em: 27 de maio de 2019.

CARVALHO, M. C. A.; PIRES, P. S.; VERÇOSA, P. A. Política de formação de professores no Estado do Acre no contexto do regime de colaboração: implicações do plano nacional de formação de professores da educação básica nas ações de qualificação do magistério acreano. 2015. Disponível em: www.enforsupunb2015.com.br/congresso /files/artigo/1426348020.doc. Acessado em 10 de jul. 2019.

GONDIM, T. G.; SILVA, J. L. A.; LIMA, M. A. R. Os desafios da formação de professores no interior do Acre e as interfaces históricas e culturais. Anais. III Seminário Internacional de Representações Sociais - Educação. PUC-PR, 2015. Disponível em: https://educere.bruc.com.br/arquivo/pdf2015/20098_9339.pdf. Acessado em: 10 mar. 2020. 
LIBÂNEO, J. C. Didática. São Paulo: Cortez, 1991.

LIMA, M. S.; PIMENTA, S. G. Estágio e docência: diferentes concepções. Revista Poíesis Pedagógica. Catalão, v. 3, n. 3 e 4, p. 5-24, 25 out. 2006. Disponível em: https://doi.org/10.5216/rpp.v3i3e4.10542. Acesso em: 10 jun. 2019.

LIMA, A. P. Educação Inclusiva e igualdade social. São Paulo: Avercamp, 2006. 